\title{
Rationality in pier geometry of Kintaikyo Bridge from viewpoint of river engineering
}

\author{
Hirokazu Sato* ${ }^{*}$
}

\begin{abstract}
The Kintaikyo Bridge, with its elegant wooden arches, has a unique pier shape and continues to be loved by residents and visitors alike. Although this bridge is an active footbridge and an important landscape element along with the Nishikigawa River and its river beach, the rationality or irrationality of the shape of its piers remains unknown. This paper is intended to clarify the river engineering characteristics of the piers for the first time by conducting 1/129 scale hydraulic model experiments. The shapes tested were a perfect spindle shape (which has been adopted as a common theory for many years) and a reconstructed current shape based on the spindle shape, and for comparison, an oval and a non-regular hexagon shape with the same width and area. The current shape, along with the spindle shape, suppressed the water level rise around the pier more than the others. As for the riverbed fluctuation, the current shape slightly increased the scour more than the others, but it also maximized the sedimentation around the scoured part. In other words, the current shape has the potential to facilitate the procurement of sediment for postflood restoration. In addition, the current shape overwhelmingly reduced the statistical dispersion associated with the experiment, suggesting that it stabilizes the trend of riverbed fluctuation even during actual floods. Based on the results, the future conservation of the Kintaikyo Bridge was also discussed.
\end{abstract}

Keywords: Kintaikyo Bridge, Pier geometry, Water level change, Riverbed fluctuations, Water cultural heritage, Landscape conservation

\section{Introduction}

The Kintaikyo Bridge (in Iwakuni City, Yamaguchi Prefecture, Japan; hereafter referred to as Kintaikyo) was built in 1673 downstream of the Nishikigawa River (hereafter referred to as the Nishikigawa) and continues to attract many people (Figs. 1, 2). The bridge body consists of three arches in the center and two girder bridges (one at each end), all of which are intricately and delicately constructed of wood (Fig. 3). Kintaikyo not only plays a practical role (a bridge for roads or sidewalks that is not washed away), but also plays a major role as a landscape element, including the clear water and river beach created by the Nishikigawa. In the vicinity of Kintaikyo, people ride on houseboats and cormorant fishing boats, admire cherry blossoms in the spring, and children play in the water in the summer. The river beach created by the Nishikigawa and Kintaikyo enhance the accessibility of the surrounding area (Fig. 3). If other types of bridges, especially piers, had continued to be selected, it is undeniable that the current landscape around Kintaikyo would have been completely different in the long term as a result of the accumulation of short-term instability of the riverbed during each flood.

Here, an overview of the value system of Kintaikyo will be given, and the author's analysis will be provided in the "Discussion" section based on the results of this study. The famous ukiyo-e $e^{1}$ artist Katsushika Hokusai and the first and second generations of Utagawa Hiroshige, all

*Correspondence: satohiro@life.shimane-u.ac.jp

Faculty of Life and Environmental Sciences, Shimane University, 1060

Nishikawatsu-cho, Matsue, Shimane 690-8504, Japan

\footnotetext{
${ }^{1}$ Ukiyo-e is a popular Japanese painting technique that emerged in the $1600 \mathrm{~s}$ and includes both original drawings and woodblock prints.
}

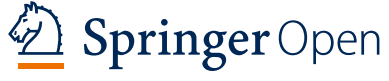

(c) The Author(s) 2021. Open Access This article is licensed under a Creative Commons Attribution 4.0 International License, which permits use, sharing, adaptation, distribution and reproduction in any medium or format, as long as you give appropriate credit to the original author(s) and the source, provide a link to the Creative Commons licence, and indicate if changes were made. The images or other third party material in this article are included in the article's Creative Commons licence, unless indicated otherwise in a credit line to the material. If material is not included in the article's Creative Commons licence and your intended use is not permitted by statutory regulation or exceeds the permitted use, you will need to obtain permission directly from the copyright holder. To view a copy of this licence, visit http://creativecommons.org/licenses/by/4.0/. The Creative Commons Public Domain Dedication waiver (http://creativeco mmons.org/publicdomain/zero/1.0/) applies to the data made available in this article, unless otherwise stated in a credit line to the data. 


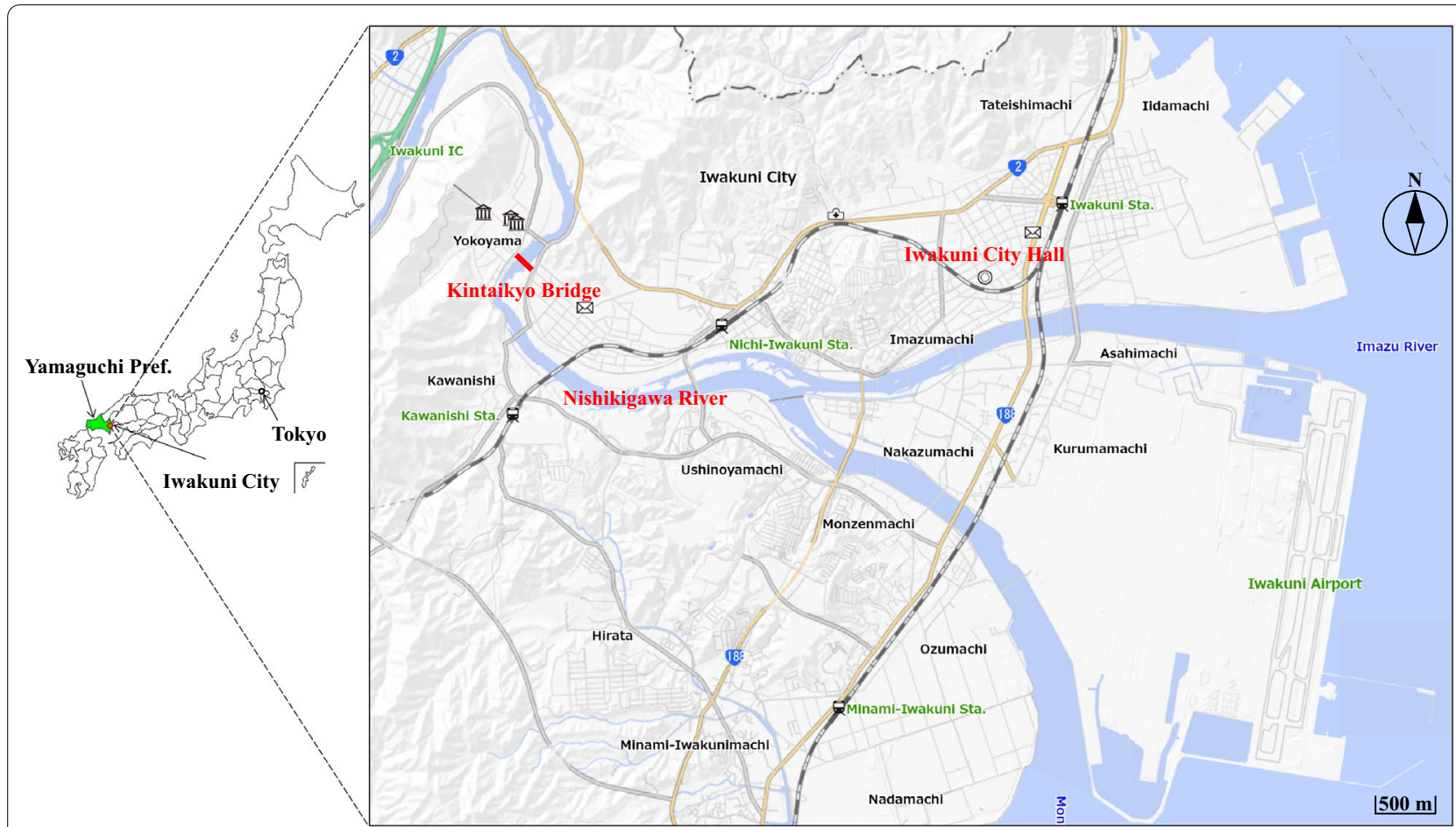

Fig. 1 Location map of Kintaikyo. Source of detailed map: GSI Maps with orientation, scale, Nishikigawa, Kintaikyo, and Iwakuni City Hall added

three of whom were active in the 1800s, also used Kintaikyo as a motif in their works. In the late 1800 s, the British businessman Gardiner traveled from around Tokyo to Kyushu in the west and wrote a travelogue with more than 80 illustrations, listing Kintaikyo as one of five bridges that highlighted the bridge itself [1].

Since then, there has been no shortage of examples of Kintaikyo drawing attention, and even the Japan Times has covered Kintaikyo in recent years [2]. Kintaikyo is also recognized as an important tourist destination in Japan, and in a survey of attractive regional topics extracted from Twitter for Hiroshima Prefecture, Kintaikyo was ranked highly despite being located in a different prefecture [3].

DeLony, who was the chief of the Historic American Engineering Record, said that wooden bridges are important in the history of human development and that Kintaikyo has the potential to become a World Heritage Site [4]. The theme of the International Day for Monuments and Sites in 2011 was "The Cultural Heritage of Water", and McIntyreTamwoy et al. of ICOMOS featured Kintaikyo alongside the world-famous Mycenaean Bridge of Kazarma, Kaju Bridge on the Zayanderud River, and Forth Bridge over the Firth of Forth [5]. Legg and Tingley [6] selected five historic wooden bridges and listed Kintaikyo as the only one from Japan with a unique design of multi-layered timber leaf springs.

The leaf springs of this unique arch are constructed by shifting many small wooden members little-by-little to create a smooth curve, which is said to be effective in reducing shear forces and vibrations transmitted through the girders [7]. These woodwork techniques have been passed down through generations of carpenters, and Ren [8] also analyzes Kintaikyo's structural strengthening ingenuity based on the transmission of the carpenters' techniques. In addition, Ren and Koshihara [9] detailed the know-how of the carpenters involved in the most recent full-scale replacement (2001-2004) and analyzed the drawings and tools to show that the carpenters used unique tools in the construction of Kintaikyo. Kuroishi [10] considers these distinctive tools to be the materialization of the mathematical rationality of the carpenters' construction practices on site.

It is believed that there is no other bridge consisting of multi-layered wooden arch shapes like those of Kintaikyo [11]. Bridge-building techniques of Kintaikyo had never been applied to any other structures due to its uniqueness and complexity; however, the Moon Bridge (built in 19121913) in the Japanese garden of the Huntington Library, San Marino was designed by Toichiro Kawai from Japan, using Kintaikyo's concept of dimensions as a reference for the design [12].

Kintaikyo, which attracts many people with its intricate structural beauty, was built to connect the castle town of Iwakuni Castle, which was separated by the Nishikigawa. It also served as part of an important national road network 


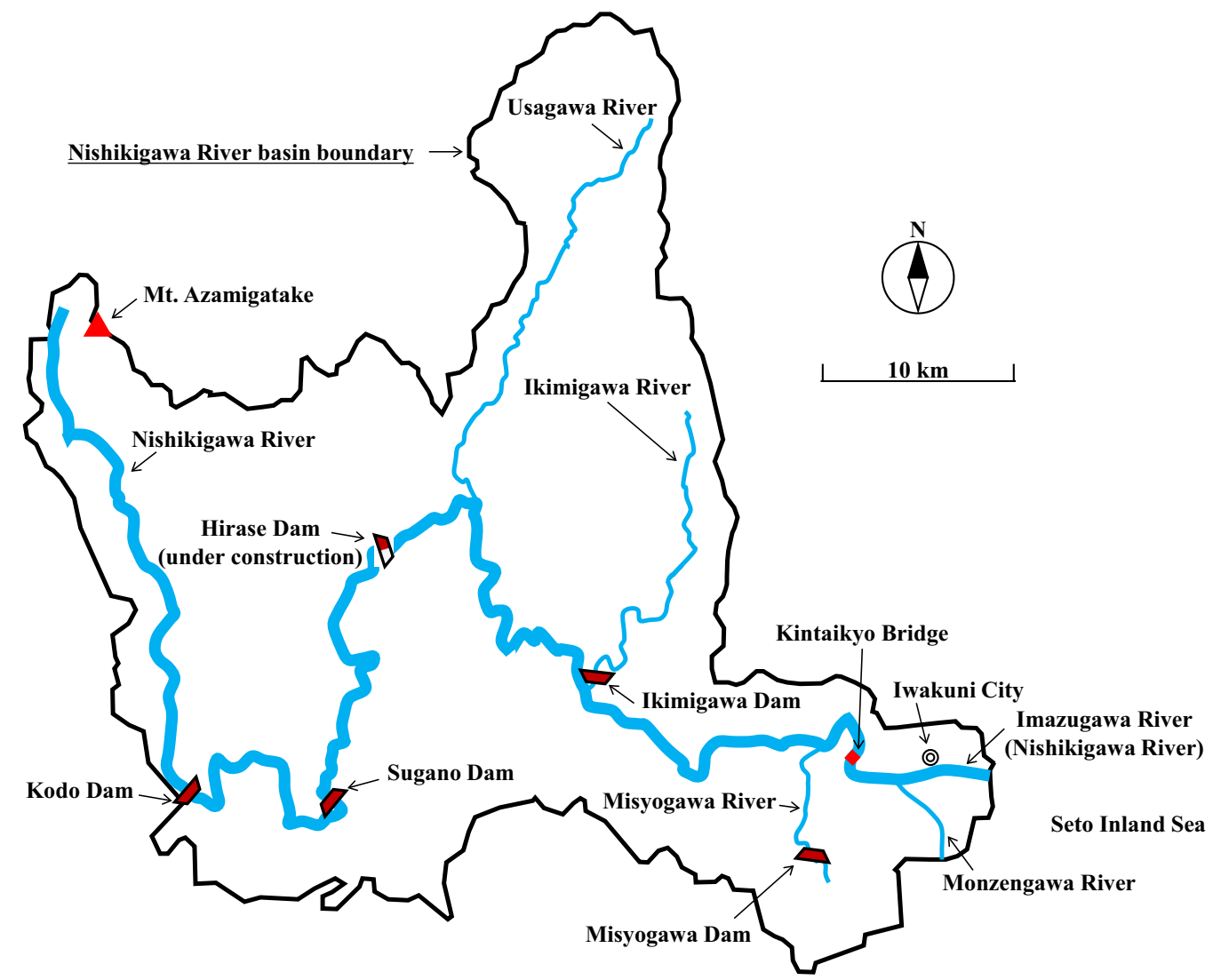

Fig. 2 Nishikigawa basin map

[13]. In 1674, 1 year after its initial construction, Kintaikyo was washed away by the Nishikigawa flood, but was rebuilt and remained unbroken for 276 years. However, it was lost in the 1950 Kezia typhoon flood and rebuilt again in 1953, and has never been completely washed away except since then. The high arches and long spans of the central parts of Kintaikyo may have the purpose of reducing the obstruction of such floodwaters and the trapping of flood-related debris (e.g., driftwood and houses) on the bridge [14]. The one-span length of the arch section is approximately $35.1 \mathrm{~m}$, which is believed to be unparalleled in the world for a wooden arch bridge [15]. Apart from rebuilding after being washed away due to flooding, Kintaikyo has also been replaced many times. The main technicians at these times were the aforementioned carpenters, and the most recent replacement was completed in 2004.

In other words, Kintaikyo has been repeatedly rebuilt after being washed away by floods, and replaced every time it became decrepit, so it does not maintain the exact same appearance as when it was first constructed. Japanese people sometimes find some beauty in this kind of endless cycle of death and rebirth, and Okuma [16] suggests that the ultimate beauty of Kintaikyo may lie in this "fragility and eternity".
In Japan, which is an island country in the hot and humid monsoon Asia, many of the representative cultural heritage sites have been repeatedly renewed and reconstructed. For example, the thatched roofs of the Gassho-zukuri (Gassho-style) houses, ${ }^{2}$ known as the symbol of the Shirakawa-go, which was registered as a World Cultural Heritage Site in 1995, have been completely replaced many times. The $\mathrm{O}$-torii, ${ }^{3}$ known as the symbol of the Itsukushima Shrine, which was also registered as a World Cultural Heritage Site in 1996, has also been rebuilt many times. Although not a World Heritage Site, the Ise Shrine, which is one of the most representative shrines in Japan, has also had its torii and other related facilities updated on a regular basis. In this way,

\footnotetext{
${ }^{2}$ Gassho is a worship gesture in which the left and right palms are put together in front of the chest. Gassho-zukuri is a traditional architectural style in Japan with a steeply pitched thatched roof whose shape resembles a gassho.

${ }^{3}$ A torii is a kind of gate at the entrance of a shrine that divides the outside into the realm of humans and the inside into the realm of gods. An O-torii is a larger scale version of a torii.
} 


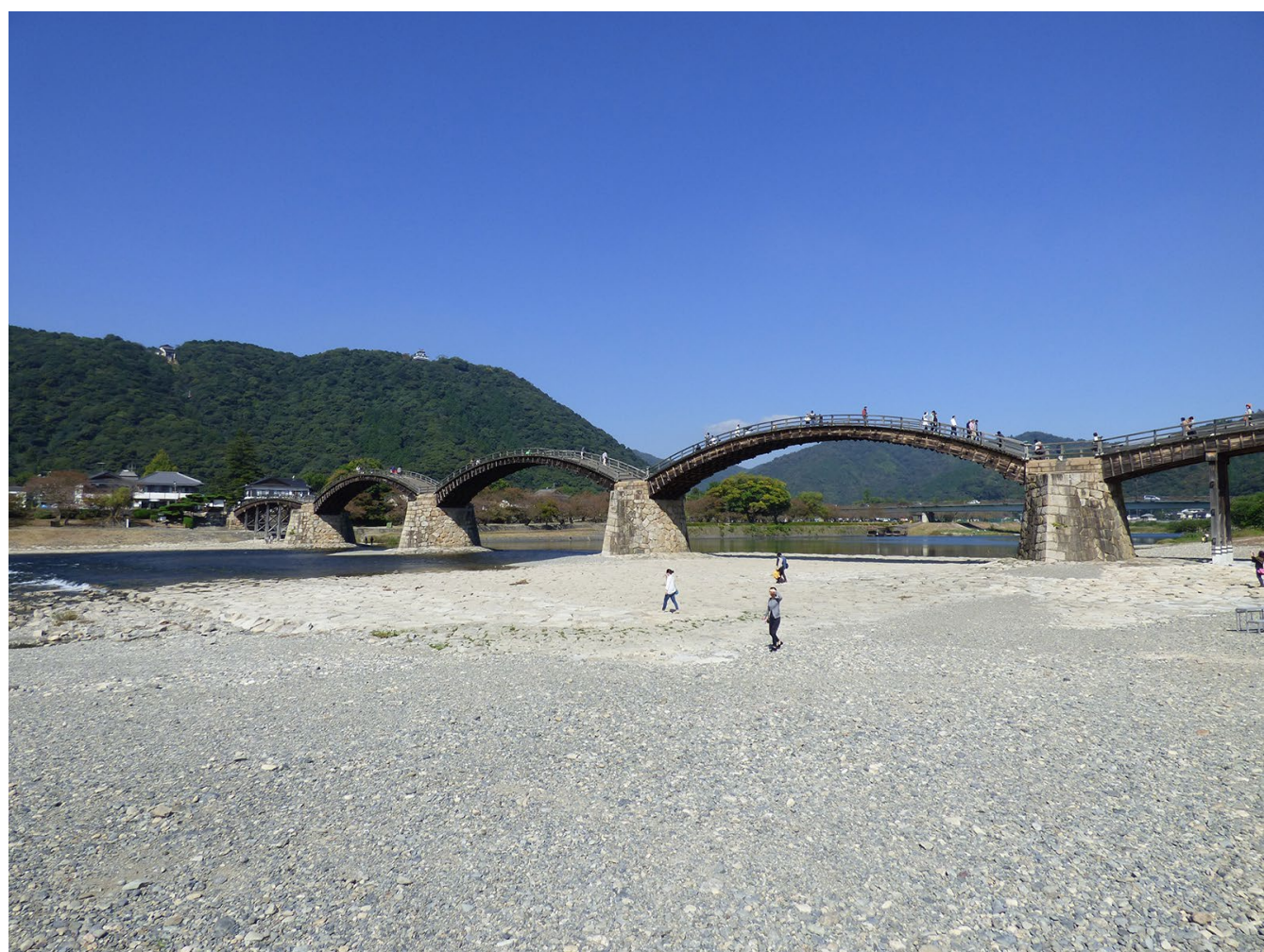

Fig. 3 Kintaikyo, Nishikigawa, and its river beach

not all cultural heritage sites in Japan are valued only for their original appearance.

"The Nara Document on Authenticity" [17] states that cultural heritage should be respected for the distinctive culture it possesses. Although Kintaikyo is not a World Heritage Site, as we have seen above, it is clearly a cultural heritage site for the region, so the Nara Document's concept is important for the future conservation, maintenance, and management of Kintaikyo. Namely, as long as "fragility and eternity" can be regarded as one of the distinctive cultures of Kintaikyo, it can be interpreted that a change from the original bridge form does not make it worthless.

Though Kintaikyo is an important landscape element, a bridge that is washed away every time it floods is useless as infrastructure. In fact, the piers of Kintaikyo were increased in height by $1 \mathrm{~m}$ during the reconstruction in 1953 and filled with concrete along with the foundation. As a result, the flow of medium-sized floods became smoother, and the safety level against collapse during an earthquake was significantly improved. In terms of bridge engineering, numerical simulations and on-site experiments using the old bridge before its last replacement have been conducted to analyze the deformation of the wooden arches of Kintaikyo [18, 19]. Furthermore, in collaboration with a local high school, attempts have been made to analyze the displacement and vibration response of the bridge body by gathering the students as a load on Kintaikyo [20, 21].

Although these technical measures and academic findings are very important for evaluating the structural mechanical rationality of Kintaikyo itself, they do not provide any information on the impact of Kintaikyo on the river (i.e., the water level rise and riverbed fluctuation during floods due to the installation of Kintaikyo piers in the Nishikigawa). In addition, this water level rise and riverbed fluctuation are also factors that are fed back to the stability of the piers. One of the elements that characterize the structure of Kintaikyo is the current pier shape (see Fig. 7a, b), which is spindle-shaped or similar. It is extremely important for the future sustainable maintenance and preservation of Kintaikyo to examine the advantages or disadvantages of why this type of pier shape was chosen by the engineers from the past. With the advancement of bridge technology, it should have been possible to replace the bridge with a more floodresistant form, but in reality, this has not been the case. The reasons for this need to be explored from the river engineering aspect as well. In this study, hydraulic model experiments were conducted as a first step to obtain 


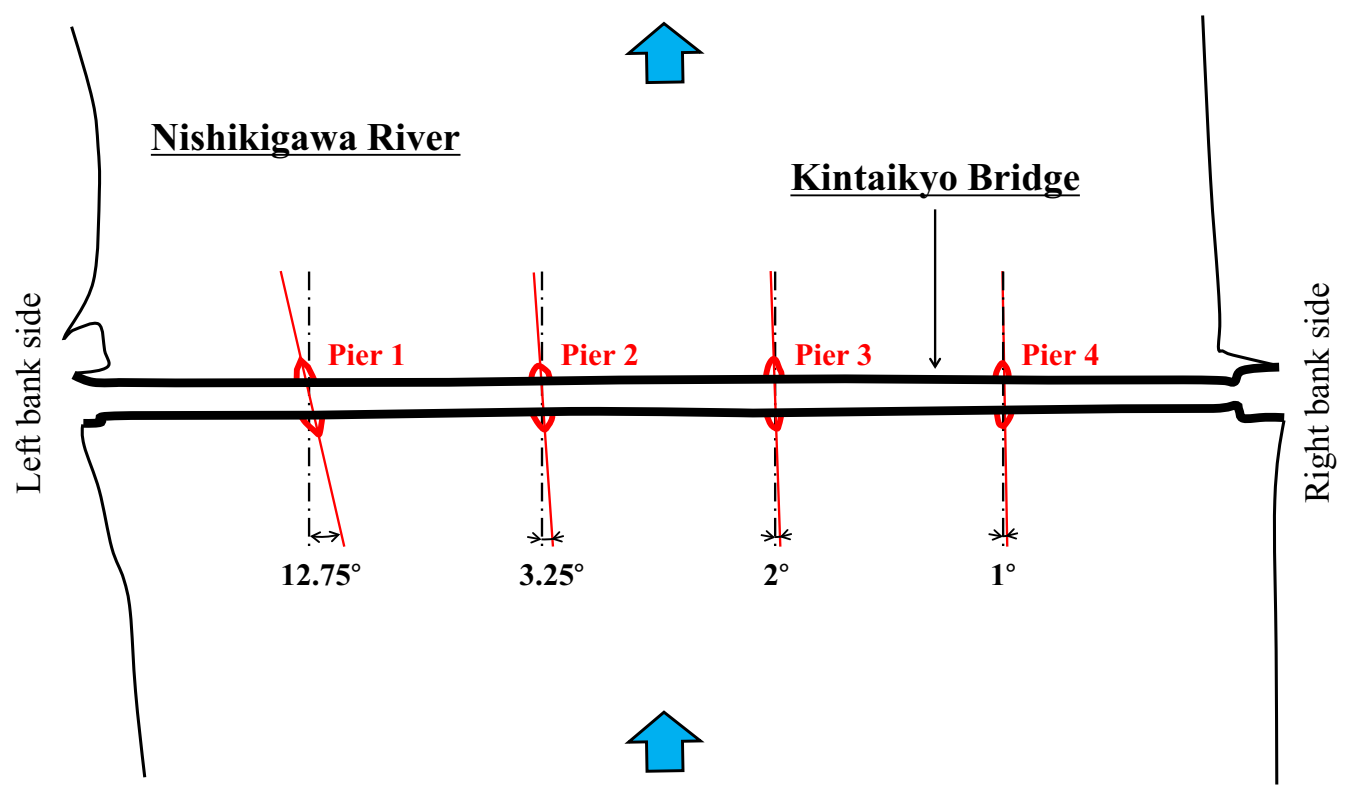

Fig. 4 Installation angles of bridge piers prior to loss in 1950. Source: Redrawn from a figure in [22]

basic knowledge on how the unique pier shape of Kintaikyo affects flood flow and riverbed fluctuations. Based on the findings, the rationality of the pier shape is discussed not only in relation to Kintaikyo itself, but also in relation to future conservation of Kintaikyo and the relationship between Kintaikyo and people.

\section{Methods}

\section{Shape of piers}

The site of Kintaikyo is thought to have been fixed from the time of its first construction in 1673, but the original shape of the piers has not been clarified. In addition, the four piers were originally not at right angles to the bridge body of Kintaikyo, and it seems that there were times when each was slightly tilted. Their angles ranged from $1^{\circ}$ to $12.75^{\circ}$ to the right bank side, which may have been adjusted to match the flow center of the Nishikigawa flood and reduce the flow resistance [22]. Figure 4 shows a schematic drawing of the installation angles. Since the reconstruction in 1953, this inclination has been eliminated - that is, the piers have been installed in the direction orthogonal to the bridge body, which seems to be roughly in line with the current flood center of the Nishikigawa.

Ingenuity to reduce flow resistance can also be seen in the shape of piers. In other words, the more streamlined the shape, the less resistance there is and the less the water level rises. It is likely that people in the past understood this empirically. However, the specific streamlined shape has not been clarified, and it has long been considered as a perfect spindle shape (see Fig. 7a) but was washed away in 1950. Later, a survey of the wreckage of the piers caused by the loss suggested that there may have been Kintaikyo's original pier shape based on the spindle shape (see Fig. 7b), and a shape with reference to the survey results was adopted for the reconstruction in 1953 and the replacement in 2004. At present, further research and studies are being carried out to try to restore a more precise pier shape, and it has been pointed out that the current bridge piers are close to it [23].

The riverbed material at the site of Kintaikyo is sand and gravel, and the riverbed slope is $1 / 500-1 / 600$, which is relatively steep. Therefore, it is important to take measures against scouring of the bridge piers, and although the original type is unknown, measures using groundsill have been taken for a long time, but they have been damaged during major floods. As for the degree of scouring, it is also considered to be suppressed by the streamlined shape as well as the water level rise.

There is still much research on riverbed fluctuations related to a pier shape, which is a typical research theme in river engineering. Lu et al. [24] studied the elliptical shape from on-site measurements and numerical calculations, while Lee et al. [25] pointed out that most of the studies on scouring of bridge piers have been conducted on simple shapes such as round columns and that few studies have been conducted on real complex shapes, so they have investigated rectangular and square shapes with hydraulic model experiments. Vonkeman et al. [26], who attempted to apply a new hydro-morphodynamic 
model to simulate scour around bridge piers, also used a simple circular shape. Wang et al. [27], who conducted hydraulic model experiments on the effectiveness of scour prevention measures using anti-scour collars, also focused on cylindrical shapes. A pier of the Gen. Elżbieta Zawacka Bridge (constructed in 2013) on the Vistula River in Poland was built on a spindle-shaped artificial island, taking into account the impact of the pier on the riverbed [28]. Although the correspondence between experimental and real river conditions was not specifically kept in mind, Vijayasree et al. [29] provided valuable information through hydraulic model experiments on the relationship between flow fields and scour geometry for local scour occurring in various non-circular patterns of pier shapes.

However, Deng and Cai [30], who conducted a huge review of research on scouring, realized that predictions of scouring fit well under certain conditions but empirical and other equations do not always fit well when experimental and field conditions change. In this way, with little information available for reference on the unique pier geometry of a bridge such as Kintaikyo, a numerical simulation approach is difficult to take at the moment. In the first place, collection of field data has been insufficient to verify the accuracy of numerical simulation. On the other hand, since on-site monitoring will take a long time, the present study undertook experiments using a hydraulic model.

\section{Hydraulic model experiments}

The experiments were conducted using an open channel in the hydraulic laboratory. Models of Kintaikyo's pier were created and installed in the sand layer in the channel, and the effects of the pier on the water level and riverbed fluctuation were investigated. As for the shape of the piers, I prepared a few comparison objects, mainly the spindle shape, which has been considered as the prototype for a long time, and the current shape based on the spindle shape. Only for the spindle shape, additional experiments with maximum angle of $12.75^{\circ}$ were implemented, because it is said that there was a time when the piers were slightly tilted to the bridge body, as mentioned above.

The target flood scale is assumed to be $4000 \mathrm{~m}^{3} / \mathrm{s}$ from the current maximum peak flood discharge of the Nishikigawa and a maximum depth of $6 \mathrm{~m}$ assuming the existence of groundsill. Kintaikyo has a length of $193.3 \mathrm{~m}$ and almost-even five spans are, but for the convenience of the experimental equipment, one span was extracted and the span length was $193.3 \div 5=38.66 \mathrm{~m}$. In the experiment, this was reproduced in the channel of $0.3 \mathrm{~m}$ width. Thus, the geometric scale is $0.3 / 38.66 \approx 1 / 129$. In addition, Froude's
Low was used for dynamic similarity. Considering this one span, the flow rate was $4000 \div 5=800 \mathrm{~m}^{3} / \mathrm{s}$, and in the experiment, $4.24 \times 10^{-3} \mathrm{~m}^{3} / \mathrm{s}$ was at steady state applied from Froude's Low. The slope of channel bed was set at 1/525 based on the slope around Kintaikyo and the adjustable range of the experimental apparatus.

The channel has a rectangular cross-section of $0.3 \mathrm{~m}$ in width and $3.5 \mathrm{~m}$ in length, with a $0.5-\mathrm{m}$-long and 0.1 -m-deep sand layer in the center, where the pier model was installed. Except for the sand layer, the channel bed was fixed with Manning's roughness coefficients of $0.01 \mathrm{~s} / \mathrm{m}^{1 / 3}$. An elevating weir was installed at $4.5 \mathrm{~m}$ from the end of the channel, and the weir height was adjusted so that the water depth was $0.047 \mathrm{~m}$ (corresponding to an actual water depth of $6 \mathrm{~m}$ ) when the sand layer part was the same roughness as the fixed bed, and the weir height was kept constant during each experiment. Each experiment took $300 \mathrm{~s}$ (equivalent to about 57 min of actual time by Froude's Low) from the start of weir raising, and the experiment was repeated three times under a same condition. For the sand layer, silica sand no. 7 with a median particle diameter of about $0.2 \mathrm{~mm}$ was used from the scale of typical local sand and gravel (several $\mathrm{mm}$ to several tens of $\mathrm{mm}$ ). It was filled with no rolling compactions in a naturally dry state (dry density: $1.40 \mathrm{~g} / \mathrm{cm}^{3}$ ) and then saturated. Figure 5 shows an overall view of the experimental apparatus, Table 1 shows the correspondence between the actual and the experiment, and Fig. 6 shows the particle size distribution of the sediment.

Six types of experimental conditions were prepared; (a) without pier (flat), (b) spindle, (c) spindle tilted by $12.75^{\circ}$, (d) current, (e) oval (rectangular with two half circles), (f) non-regular hexagon (rectangular with two equilateral triangles). The actual piers have a three-dimensional shape that changes in the height direction, but it was difficult to reproduce them exactly on this experimental scale, so the model had a uniform shape in the height direction. The dimensions of the model were based on the spindle shape that has been considered for a long time, and the length and other aspects were adjusted so that the width and area of the piers were the same (Fig. 7). As a side note, the model piers were made of colored wood with a non-water repellent spray.

The measurement items were the water level at the six points (see Fig. 5) and the change in sand layer thickness. The water level was measured with ultrasonic water level gauges (sampling rate: $100 \mathrm{~Hz}$ ), and the sand layer thickness was measured with a point gauge. The measurement points of the sand layer thickness were set around the pier model, which coincided with the installation range of the water level gauges, in order to avoid the influence 


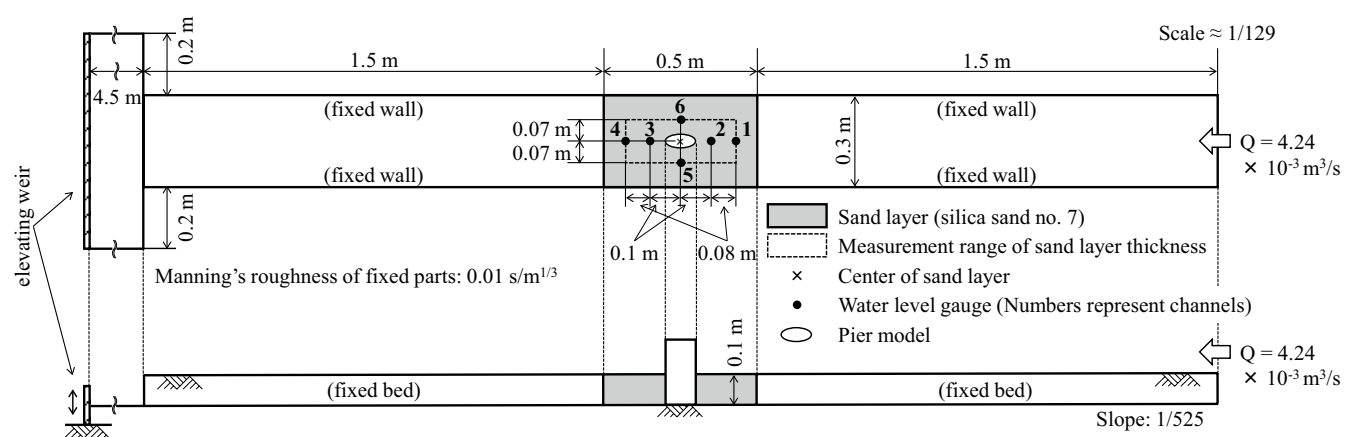

Fig. 5 Overall view of experimental apparatus, with water level measurement points

Table 1 Specifications of experimental values

\begin{tabular}{lll}
\hline Hydraulic conditions & Prototype & Model \\
\hline Water surface width $(\mathrm{m})$ & $193.3 / 5=38.66$ & 0.3 \\
Geometric scale & $0.3 / 38.66 \approx 1 / 129$ & \\
Peak discharge $\left(\mathrm{m}^{3} / \mathrm{s}\right)$ & $4000 / 5=800$ & $4.24 \times 10^{-3}$ \\
Peak water depth $(\mathrm{m})$ & 6 & 0.047 \\
Peak mean flow velocity $(\mathrm{m} / \mathrm{s})$ & 3.445 & 0.304 \\
Froude number & 0.45 & \\
Manning's roughness $\left(\mathrm{s} / \mathrm{m}^{1 / 3}\right)$ & 0.022 & 0.010 \\
Bed slope & $1 / 500-1 / 600$ & $1 / 525$ \\
Duration of flood peak $(\mathrm{min})$ & 57 & 5 \\
\hline
\end{tabular}

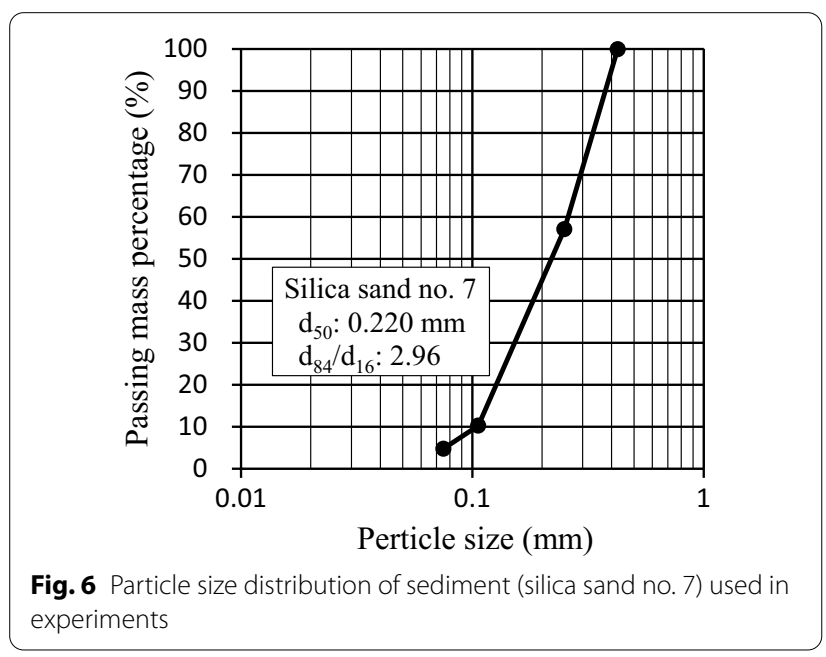

of the fixed boundary (fixed wall) around the sand layer area (Fig. 8). The number of measurement points is 65-92, depending on the pier geometry.

\section{Results}

\section{Changes of water level}

The datum of water level is the channel bed of the downstream water level gauge ch. 4 (see Fig. 5). The temporal variation of water level is shown in Fig. 9, and the spatial distribution of water level at the end of the experiment is shown in Fig. 10. All values are the means of the experiment repeated three times. Noise in the measured water level was removed by a 3-s median filter, and negative values were excluded.

Comprehensively looking at these results, it can be seen that the current shape suppresses the rise in water level most in the front, back, left, and right of the pier. It seems that the water level rise is generally suppressed in the order of strong streamlinedness; spindle, non-regular hexagon and oval. On the other hand, as at ch. 1 and ch. 4 , the range of water level change of current shape expands as the distance from the pier area increases, and the spindle shape stabilizes the water level over a wide range. In other words, it was suggested that the current shape is advantageous for reducing the burden on the piers, and the spindle is advantageous for reducing the risk of inundation in the castle town around Kintaikyo. In the case of current shape, the cause of the highest water level at ch. 1 in the most upstream part could not be identified. It can be said that the non-regular hexagon type and oval type used for comparison do not have any particular advantage from these two viewpoints.

In some cases, the water levels of the symmetrically located gauges ch. 5 and ch. 6 differed significantly, but it is difficult to interpret these differences. It is possible that the subtle bias of the experimental apparatus caused the sand layer to fluctuate more than the opposite side, resulting in a water level difference on either side of the pier.

When the spindle shape was tilted by $12.75^{\circ}$ (i.e. the direction of the piers is shifted from the flow center), it can be seen that the overall rise in water level is larger 

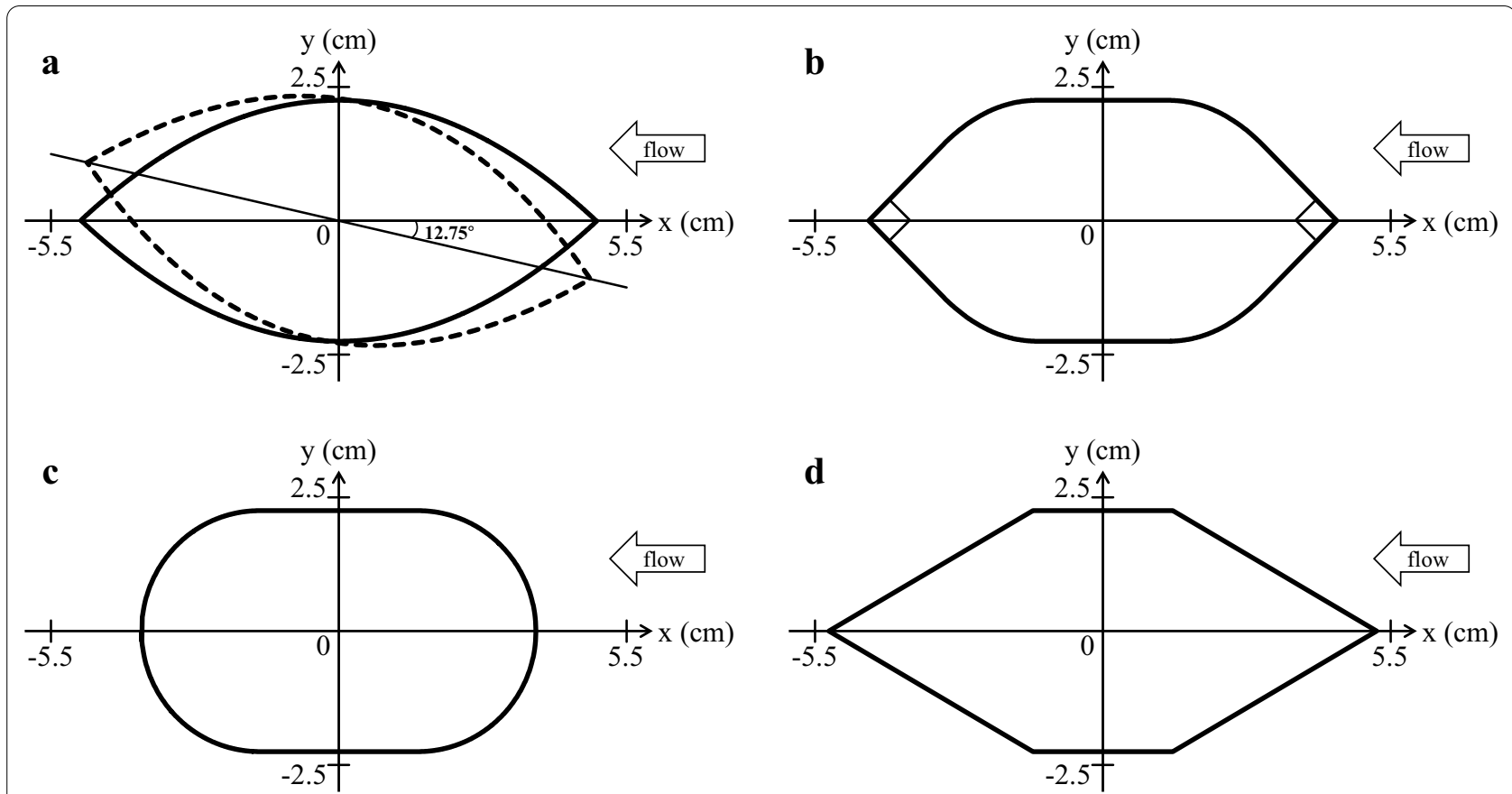

Fig. 7 Model of bridge pier. a Spindle (a model tilted by $12.75^{\circ}$ is also shown). b Current. c Oval. d Non-regular hexagon. Curved parts in a and $\mathbf{b}$ are approximated by quadratic and cubic curves, respectively. Curves in $\mathbf{c}$ are both semicircles. Triangles in $\mathbf{d}$ are both equilateral
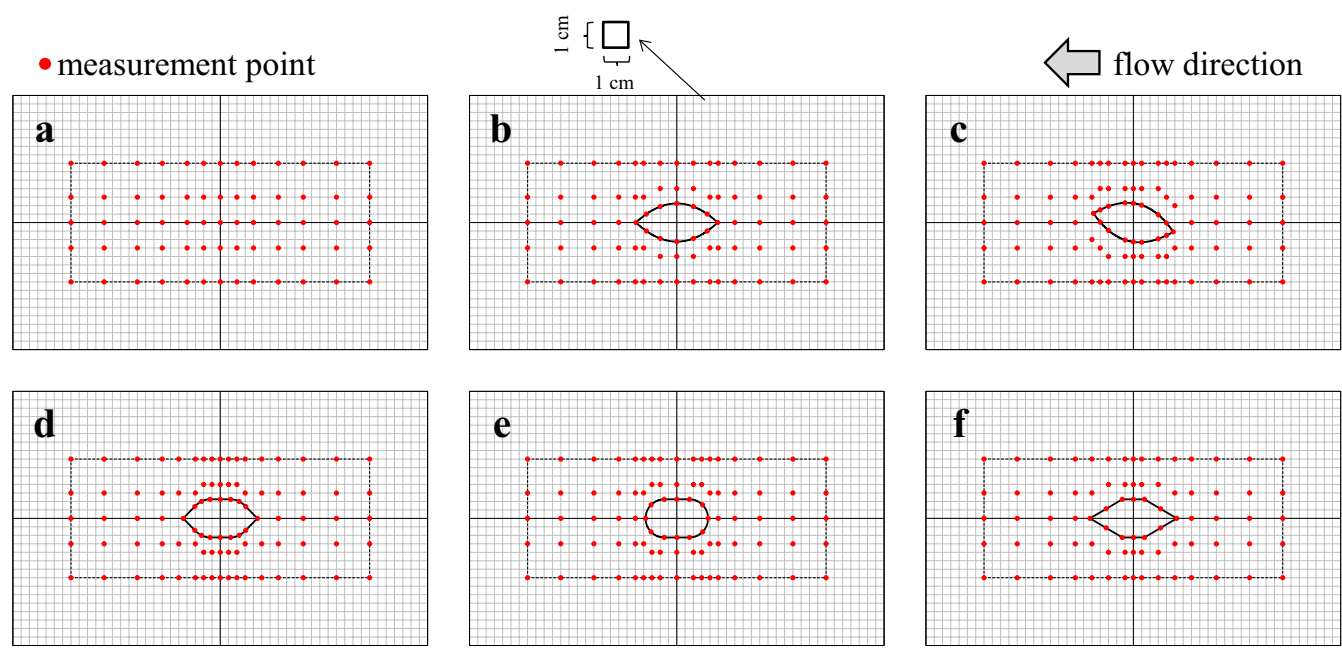

Fig. 8 Measurement point of sand layer thickness. a Without pier (flat). b Spindle. c Spindle tilted by $12.75^{\circ}$. d Current. e Oval. f Non-regular hexagon

than with no tilting. Since this tendency is likely to be the same for any other shape, it is highly likely that the engineers involved adjusted the piers to fit the flow center of the Nishikigawa, instead of making them perpendicular to the bridge body. For reference, setting the angle to $45^{\circ}$ was also tried in this study, but the pier model was washed away due to heavy scouring.

\section{Changes of sand layer thickness}

Figure 11 shows the state of the sand layer after the end of the experiments, and Fig. 12 and Table 2 show the amount of change in the sand layer thickness. Looking at these, it is clear that local scour/sedimentation did not occur when there was no pier (flat), whereas scour occurred in the surrounding area when the pier was 


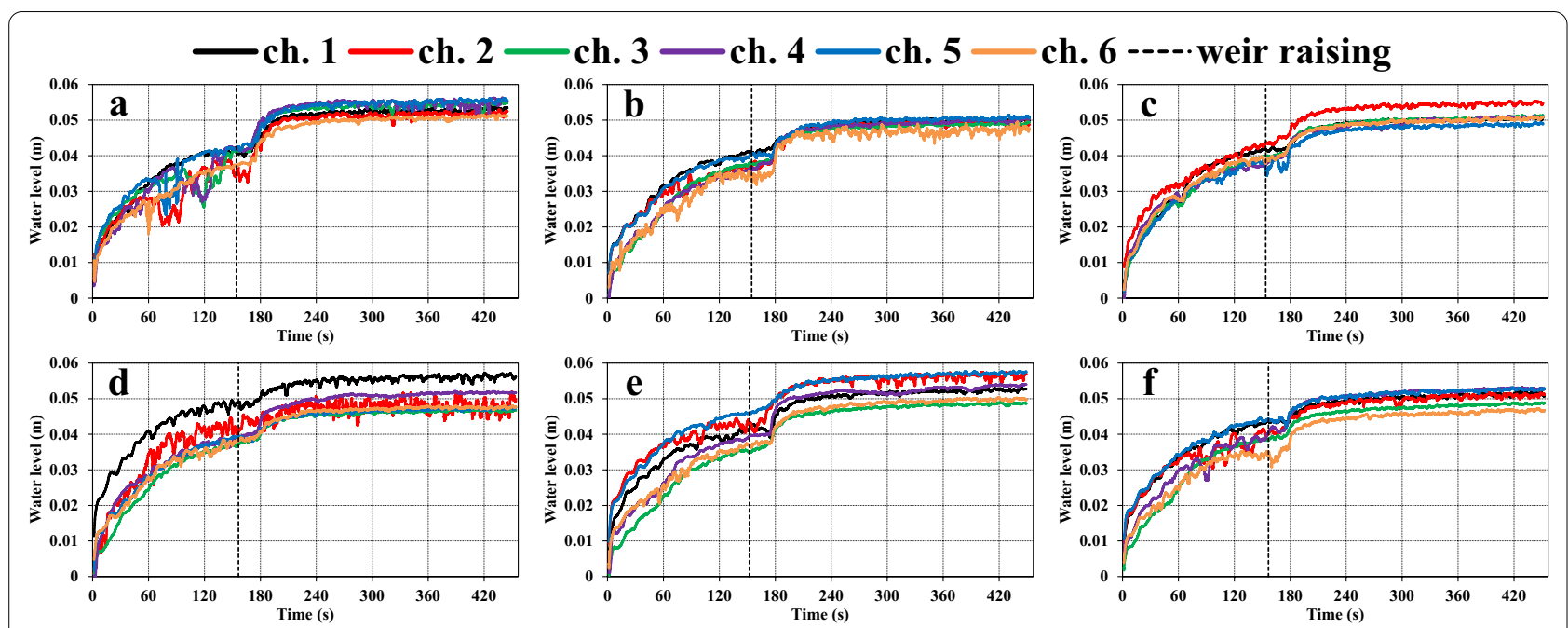

Fig. 9 Temporal variation of water level. a Without pier (flat). b Spindle. c Spindle tilted by $12.75^{\circ}$. d Current. e Oval. f Non-regular hexagon. Water level datum: channel bed at gauge ch. 4. Mean of three experiments

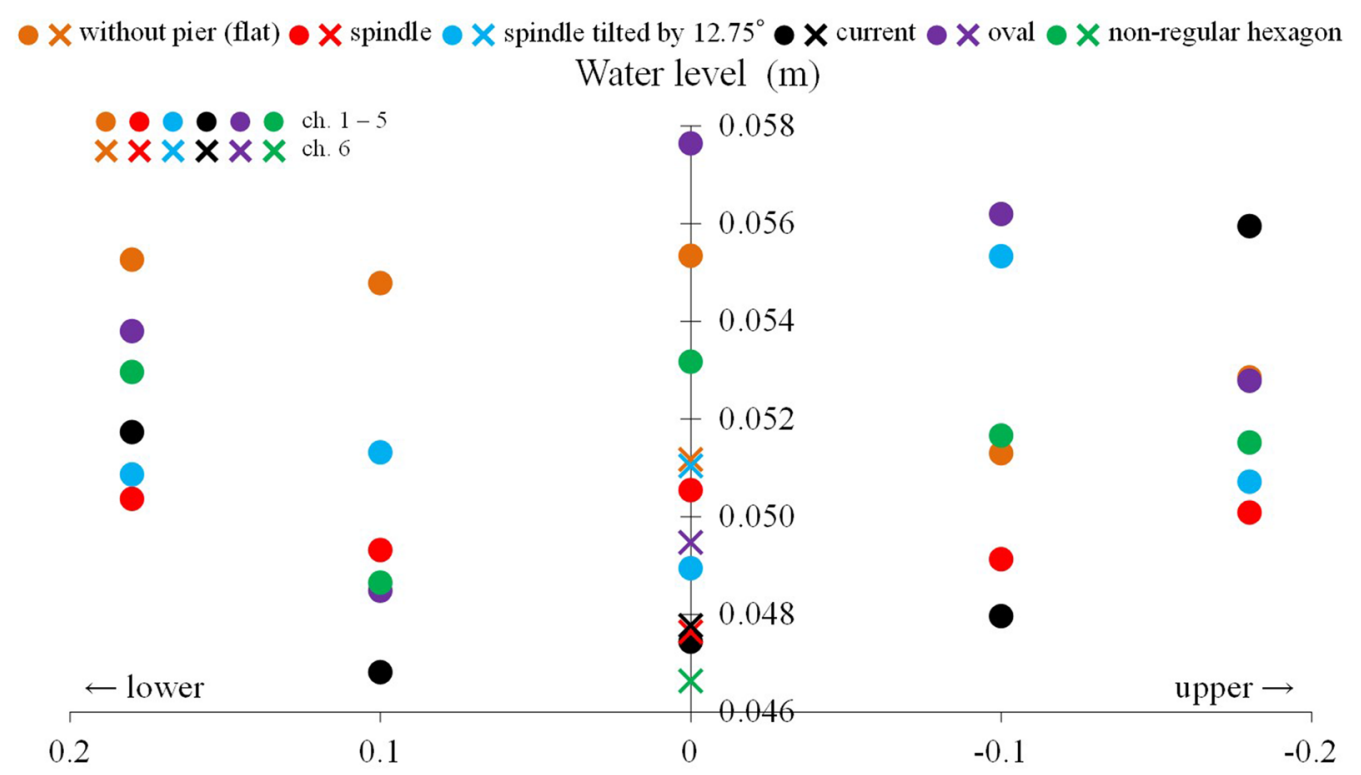

Distance from center of pier $(\mathrm{m})$

Fig. 10 Spatial distribution of water level at end of experiment. Water level datum: channel bed at gauge ch. 4. Mean of three experiments

installed. The mean maximum scour of the three experiments was the highest for the current and the lowest for the spindle, with a difference of about $2.6 \mathrm{~mm}$, and no extreme differences occurred when comparing the whole results.

This difference of $2.6 \mathrm{~mm}$ is converted to about $34 \mathrm{~cm}$ in actual scale, but the results of this experiment show that scour of about $4.7 \mathrm{~mm}$ (actual depth equivalent: about $61 \mathrm{~cm}$ ) can occur even without piers during a major flood near Kintaikyo. This is within the range of the scour scale that can be actually observed. In addition, it is about $6 \%$ for the average maximum scour of $41.7 \mathrm{~mm}$ (actual depth conversion: about $5.4 \mathrm{~m}$ ), which is within the order of error that occurs in riverbed fluctuation prediction using current hydraulic knowledge.

In contrast, in all cases, scour occurs mainly around the pier, but sedimentation occurs around the scoured area. For the maximum value of the three experimental means, the current shape is the next largest after the oval. It can thus be said that, in the current shape, repair materials 


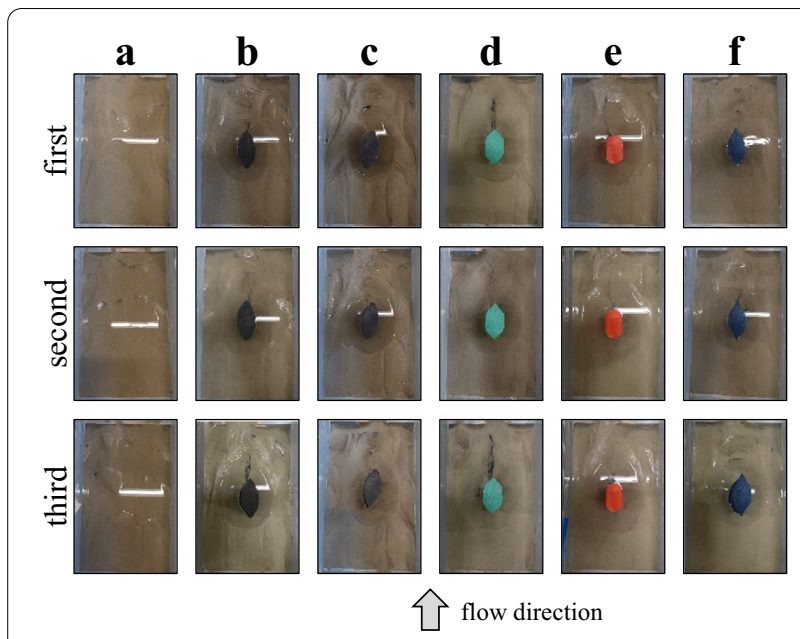

Fig. 11 Photographs of change in sand layer thickness at end of experiment. a Without pier (flat). b Spindle. c Spindle tilted by $12.75^{\circ}$. d Current. e Oval. f Non-regular hexagon

for the scoured part can be procured to some extent in the vicinity.

When the spindle shape was tilted, the maximum scour of the mean of three experiments was larger and the sedimentation was smaller. Therefore, again, it can be seen that if the pier deviates from the flow center, it is disadvantageous from the aspect of riverbed fluctuation.

Incidentally, even if including other traditional shapes that are commonly seen (e.g., different tip shapes upstream and downstream), if the pier shape is streamlined and the installation angle relative to the flow center is also small, both the water level rise and riverbed fluctuations are expected to be small in magnitude, but more detailed verification is needed for the effects of shape asymmetry.

\section{Discussion}

As we have seen, Kintaikyo's pier shape has some significant points in terms of water level rise compared to other shapes, and it is suggested that it does not produce extreme scour. Below the mean values shown in Table 2, the $95 \%$ confidence intervals are also given in parentheses. This value can be used as an indicator to consider the statistical dispersion of experimental values. The current shape has by far the smallest value of this for both scour and sedimentation compared to the other shapes.

In actual riverbed fluctuations, small differences in the riverbed can cause large differences in scour and sedimentation, even when the same flood arrives in the same river. Therefore, predicting riverbed changes is more difficult than predicting flood water levels and flows. If the structure is installed on the actual riverbed in such an unstable situation, the instability of the riverbed

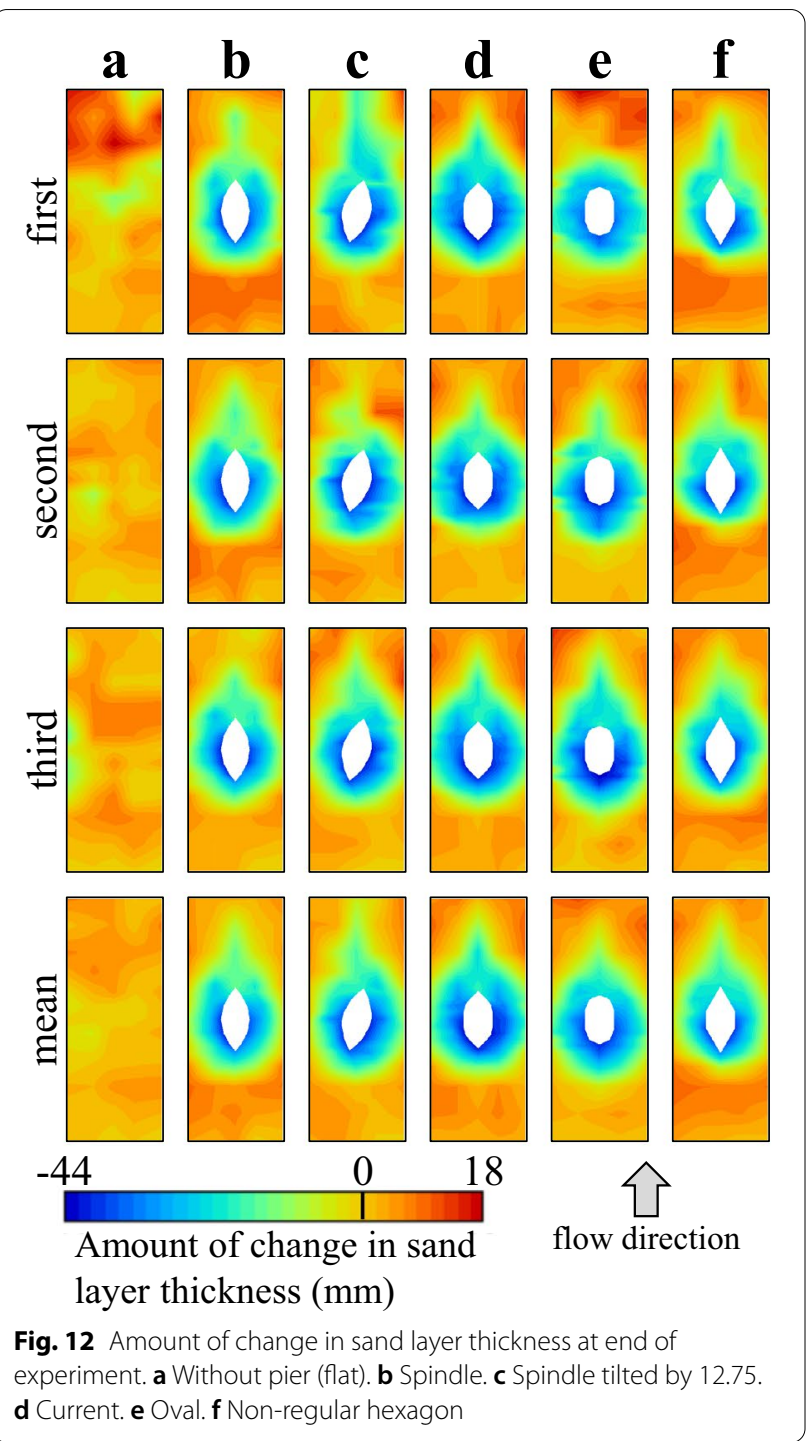

fluctuation will be further increased, but it is considered that the current shape may relatively stabilize the riverbed fluctuation during the flood. From the statistical dispersion in the experiments, it can be deduced that the current shape created conditions that made predictions of riverbed fluctuations around the piers and recovery measures after flooding easier.

People become familiar with the Nishikigawa and Kintaikyo during normal times, not during floods. So far, there are four dams with flood control purposes in the Nisikigawa basin. One of them is located in the upper reaches of the main stream of the Nishikigawa, and the Hirase Dam as the fifth dam with flood control purpose is under construction a little downstream of it. The Hirase Dam has the largest flood control capacity among these five dams, with a catchment area of $336.2 \mathrm{~km}^{2}$, accounting for nearly $40 \%$ of the $889.8 \mathrm{~km}^{2}$ 
Table 2 Maximum change in sand layer thickness

\begin{tabular}{|c|c|c|c|c|}
\hline \multirow[t]{2}{*}{ Pier geometry } & \multicolumn{2}{|c|}{$\begin{array}{l}\text { Maximum scour } \\
(\mathrm{mm})\end{array}$} & \multicolumn{2}{|c|}{$\begin{array}{l}\text { Maximum } \\
\text { sedimentation }(\mathrm{mm})\end{array}$} \\
\hline & Each expt & $\begin{array}{l}\text { Mean } \\
(95 \% \mathrm{Cl})\end{array}$ & Each expt & $\begin{array}{l}\text { Mean } \\
(95 \% \mathrm{Cl})\end{array}$ \\
\hline \multirow[t]{3}{*}{ Without pier (flat) } & -12.4 & \multirow{3}{*}{$\begin{array}{l}-4.7 \\
(23.71)\end{array}$} & 18.0 & \multirow{3}{*}{$\begin{array}{l}6.8 \\
(18.96,20.65)\end{array}$} \\
\hline & -10.0 & & 7.6 & \\
\hline & -15.6 & & 7.6 & \\
\hline \multirow[t]{3}{*}{ Spindle } & -38.0 & \multirow{3}{*}{$\begin{array}{l}-39.1 \\
(3.04)\end{array}$} & 10.0 & \multirow{3}{*}{$\begin{array}{l}8.7 \\
(5.74)\end{array}$} \\
\hline & -38.8 & & 10.0 & \\
\hline & -40.4 & & 10.0 & \\
\hline \multirow{3}{*}{$\begin{array}{l}\text { Spindle tilted by } \\
12.75^{\circ}\end{array}$} & -40.4 & \multirow{3}{*}{$\begin{array}{l}-40.7 \\
(3.04)\end{array}$} & 13.2 & \multirow{3}{*}{$\begin{array}{l}7.9 \\
(11.64)\end{array}$} \\
\hline & -40.4 & & 11.6 & \\
\hline & -42.0 & & 14.0 & \\
\hline \multirow[t]{3}{*}{ Current } & -42.0 & \multirow{3}{*}{$\begin{array}{l}-41.7 \\
(1.15)\end{array}$} & 13.2 & \multirow{3}{*}{$\begin{array}{l}10.8 \\
(1.19)\end{array}$} \\
\hline & -41.2 & & 11.6 & \\
\hline & -42.0 & & 10.0 & \\
\hline \multirow[t]{3}{*}{ Oval } & -37.2 & \multirow{3}{*}{$\begin{array}{l}-40.4 \\
(7.95)\end{array}$} & 18.0 & \multirow{3}{*}{$\begin{array}{l}11.1 \\
(15.44)\end{array}$} \\
\hline & -42.0 & & 10.8 & \\
\hline & -43.6 & & 13.2 & \\
\hline \multirow[t]{3}{*}{ Non-regular hexagon } & -38.8 & \multirow{3}{*}{$\begin{array}{l}-39.3 \\
(2.29)\end{array}$} & 10.0 & \multirow{3}{*}{$\begin{array}{l}10.0 \\
(1.99)\end{array}$} \\
\hline & -40.4 & & 10.8 & \\
\hline & -41.2 & & 10.8 & \\
\hline
\end{tabular}

Values in parentheses represent $95 \% \mathrm{Cl}$

basin area at the Garyobashi flood control reference point of the Nishikigawa just downstream of Kintaikyo. This will result in sediment trapping in its dam reservoir reducing the sediment supply to the riverbed around Kintaikyo. This means that the usual landscape of the river beach will change, and the Nishikigawa's own sediment will become more valuable in the near future. Therefore, a pier shape that makes the riverbed fluctuations unstable and unpredictable for each flood is not desirable for sediment management of the riverbed after the construction of the Hirase Dam. In this regard, as discussed above, the experimental results in this study (see 95\% confidence intervals in Table 2) indicate that the current pier shape suppresses the variability of riverbed fluctuations the most and thus may be beneficial for medium- to long-term riverbed management around Kintaikyo.

For the protection of other historic bridge piers from floods, including riverbed fluctuations, it may be beneficial to make them as streamlined as possible if shape changes are allowed. If it is not easy to change the shape from the viewpoints of authenticity, etc., it is effective to install groundsills and strong foundation works that do not interfere with the landscape or to control the river flood flow upstream. However, the use of flood control facilities requires careful assessment and ex-post monitoring of changes in sediment circulation and the natural environment.

Kitaikyo itself has had a history of changes in its appearance since it was built, as the transmission of carpentry skills has responded to changes in the Nishikigawa and the castle town, the development of Iwakuni City, and so on. On the other hand, the value of this landscape element is universal, as it has been loved by many people since ancient times, even if its shape does not remain the same. Therefore, Kintaikyo may continue to maintain its identity, as long as it remains an active bridge and continues to be loved by people. However, it is for this reason that we must be able to explain the form of Kitanikyo as a structure, not only in terms of its characteristic wooden arches, but also in terms of the rationality of the piers that support it. The exact process of change in the shape, construction method, and installation angle of the piers of Kintaikyo is still under investigation, but it is necessary to find some kind of authenticity in the piers themselves.

This study seems to have provided some information as a first step in explaining the unknown rationality in considering the authenticity of the pier geometry of Kintaikyo. However, there remain shortcomings in that the number of experiments was limited and that there was no choice but to use a single pier model due to the nature of the equipment used. In addition, the shape of the piers is approximated in two dimensions in the vertical direction, and it would be worthwhile to improve the system to reproduce all four piers in three dimensions in the future. On the other hand, it is difficult to examine many conditions only by hydraulic model experiments, considering the intensification of flood external force and the impact of the construction of the Hirase Dam, which are of concern in the future. The prediction of such mediumto long-term impacts will rely heavily on numerical simulation models. The results of this and future advanced experiments, along with the results of data monitoring in the Nishikigawa, which is expected to accumulate, will play an important role also in the calibration of numerical simulations.

\section{Conclusions}

The river engineering characteristics of Kintaikyo's uniquely shaped piers were clarified from hydraulic model experiments. In the experiments, one of the four piers was installed in an open channel to reproduce the largest class of flood of the Nishikigawa. As the pier shapes, a perfect spindle shape that had been assumed for a long time, and a current shape, in addition to them, an oval shape and a non-regular hexagon shape were prepared, and the water level rise and the sand layer's scour/ sedimentation around the pier were investigated. Results show that (1) the water level rise around the pier was the 
lowest in the current shape, (2) the degree of scour was larger in the current shape, but it was within the error range of the actual riverbed fluctuation, (3) at the same time, the sedimentation is larger around the scoured area, which makes it easier to procure materials from nearby areas for post-flood repair, and (4) the current shape has the least statistical dispersion in the experimental mean values of sand layer's fluctuation, which makes it easier to predict the actual riverbed fluctuations for each flood.

The spindle shape was also judged to have the same overall advantage as the current shape in terms of water level rise and scour, but no special advantage was found in the other shapes. In other words, the spindle shape, which has been thought for a long time, and the current shape similar to it, were judged to be reasonable for river management in terms of water level rise and riverbed fluctuation. It was also confirmed that when the pier angle was shifted from the flow center of the Nishikigawa, the water level rose and the river bed fluctuated to a greater extent, suggesting that successive generations of engineers (mainly carpenters) had closely observed the floods in the Nishikigawa.

The stability of Kintaikyo is important for the future preservation of its nearby river beach, and the shape of the current piers is expected to play an important role in this in the medium to long term. In other words, the potential of the current shape to stabilize riverbed fluctuations seems of particular value in dealing with the expected future intensification of the Nishikigawa floods and the reduction in sediment supply due to sediment trapping by the large dam being constructed upstream.

\section{Acknowledgements}

Not applicable.

\section{Authors' contributions}

The author has conducted all of this research and written the manuscript. The author read and approved the final manuscript.

\section{Funding}

Not applicable.

Availability of data and materials

Please contact the corresponding author for data requests.

\section{Declarations}

\section{Competing interests}

The author declares no conflict of interest.

Received: 31 May 2021 Accepted: 17 August 2021

Published online: 26 August 2021

\section{References}

1. Gardiner RS. Japan as we saw it. Boston: Rand Avery Supply Company; 1892.

2. Powell SJ. Kintaikyo: a bridge reincarnated over troubled waters. In: The Japan Times; 2014; 2014.
3. Sakai T, Tamura K, Kitakami H. Extracting attractive local-area topics in georeferenced documents using a new density-based spatial clustering algorithm. IAENG Int J Compt Sci. 2014;41(3):131-40.

4. DeLony E. Context for world heritage bridges. ICOMOS-TICCIH; 1996.

5. McIntyre-Tamwoy S, Orive O, Kolonias SA, Selfslagh B. 18 April 2011 International day for monuments and sites: the cultural heritage of water. ICOMOS (Website) 2011:1-24.

6. Legg C, Tingly D. Viability of modern timber highway bridges. Wood Research \& Development; 2020.

7. Koshihara M. Wooden heritage seen with an architectonic eye: Kintai-kyō Bridge. In: Fujimori T, Fujitsuka M, editors. Japan's wooden heritage. Chiyoda: JAPAN LIBRARY; 2017. p. 191.

8. Ren C. A timber bridge constructed in seventeenth-century Japan: study of innovation in the construction of Kintai Bridge and its maintenance techniques. In: Proceedings of the 6th international congress on construction history; 2018 July 9-13; Brussels, Belgium; 2018.

9. Ren C, Koshihara M. A study on the construction History of Kintai Bridge in Japan. J Asian Archit Build Eng. 2017;16(2):255-61. https://doi.org/10. 3130/jaabe.16.255.

10. Kuroishi I. Mathematics of carpentry in historic Japanese architecture. In: Williams K, Ostwald M, editors. Architecture and mathematics from antiquity to the future. Cham: Birkhäuser; 2015. p. 333-47. https://doi.org/10. 1007/978-3-319-00137-1_23.

11. Yang $Y$, Chen $B C$, Nakamura $S$, Nishikawa T. Structural form of timber arch bridges and research value of a Chinese woven timber arch. In: Proceedings of the 8th international conference on arch bridges; 2016 Oct 5-7; Wrocław, Poland; 2016.

12. Liu Y. A full moon in another land: the Moon Bridge in the Japanese garden of the Huntington Library. Front Archit Res. 2020;9(3):556-67. https:// doi.org/10.1016/j.foar.2020.02.004

13. Isohata $\mathrm{H}$. Civil engineering heritage: country profile—Japan. Eng Hist Hérit. 2016;169(2):95-100. https://doi.org/10.1680/jenhh.16.00004.

14. Fujimori T. Kintai-kyō Bridge: 35 -meter arches flying across the sky. In: Fujimori T, Fujitsuka M, editors. Japan's wooden heritage. Chiyoda: JAPAN LIBRARY; 2017. p. 26-30.

15. Fujitsuka M. Photographer's notes: cross and you'll understand. In: Fujimori T, Fujitsuka M, editors. Japan's wooden heritage. Chiyoda: JAPAN LIBRARY; 2017. p. 31-3.

16. Okuma T. Fragility and eternity. In: Advisory Committee of World Heritage Registration for Kintaikyo Bridge, editors. The finest masterpiece of a bridge: Kintaikyo-Bridge, Iwakuni: Kintaikyo Bridge Section, Iwakuni City; 2016, pp. 1-3 in preface.

17. ICOMOS. The Nara document on authenticity. ICOMOS; 1994

18. Yoda T. Investigation of mechanical behavior of the Japanese historical timber arch bridge: Kintaikyo Bridge. In: Proceedings of the 6th international conference on arch bridges; 2010 Oct 11-13; Fuzhou, China; 2010.

19. Yoda T, Matsutsuka N, Wada A. Sustainable technology of the Japanese historical timber footbridge-The Kintaikyo Bridge. In: Proceedings of the 5th international conference: footbridge 2014-past, present \& future; 2014 Jul 16-18; London, United Kingdom; 2014.

20. Tomioka S, Tomoda T, Yoda T. Design of arch and transfer of technology in Kintaikyo-bridge. In: Proceedings of the IABSE conferece, Nara 2015: elegance in structures; 2015 May 13-15; Nara, Japan; 2015. https://doi. org/10.2749/222137815815773918.

21. Tomioka S, Yoda T. Design and periodic inspection of the Kintai-kyo wooden arch bridge. Struct Eng Int. 2018;26(4):341-7. https://doi.org/10. 2749/101686616X14676302919999.

22. Ono T. On the historical sketch \& the reconstruction work of Kintai-Kyo, JSCE Magazine. Civil Eng. 1936;22(5):515-33 (in Japanese).

23. Matsumura H. Position of Kintaikyo Bridge in history of bridges in Japan. In: City l, editor. Research report on Kintaikyo Bridge. Iwakuni: Iwakuni City; 2020. p. 102-47 (in Japanese).

24. Lu J-Y, Hong J-H, Su C-C, Wang C-Y, Lai J-S. Field measurements and simulation of bridge scour depth variations during floods. J Hydraul Eng. 2008;134(6):810-21. https://doi.org/10.1061/(ASCE)0733-9429(2008)134: 6(810).

25. Lee SO, Abid I, Hong SH. Effect of complex shape of pier foundation exposure on time development of scour. Environ Fluid Mech. 2021;21:103-27. https://doi.org/10.1007/s10652-020-09765-3. 
26. Vonkeman JK, Basson GR, Smit GJF. Hydro-morphodynamic modelling of local bridge pier scour in alluvial beds. In: Proceedings of the 18th international conference on transport and sedimentation of solid particles; 2017 Sep 11-15; Prague, Czech Republic; 2017.

27. Wang S, Wei K, Shen Z, Xiang Q. Experimental investigation of local scour protection for cylindrical bridge piers using anti-scour collars. Water. 2019:11(7):1515. https://doi.org/10.3390/w11071515.

28. Sobala D, Wąchalski K. Modern solution for the foundation of Poland's largest arch bridge. In: Proceedings of the 8th international conference on arch bridges; 2016 Oct 5-7; Wrocław, Poland; 2016.

29. Vijayasree BA, Eldho TI, Mazumder BS, Ahmad N. Influence of bridge pier shape on flow field and scour geometry. Int J River Basin Manag. 2019:17(1):109-29. https://doi.org/10.1080/15715124.2017.1394315.
30. Deng L, Cai CS. Bridge scour: prediction, modeling, monitoring, and countermeasures - review. Pract Period Struct Des Constr. 2010;15(2):125-34. https://doi.org/10.1061/(ASCE)SC.1943-5576.0000041.

\section{Publisher's Note}

Springer Nature remains neutral with regard to jurisdictional claims in published maps and institutional affiliations.

\section{Submit your manuscript to a SpringerOpen ${ }^{\circ}$ journal and benefit from:}

- Convenient online submission

- Rigorous peer review

- Open access: articles freely available online

- High visibility within the field

- Retaining the copyright to your article

Submit your next manuscript at $\boldsymbol{\nabla}$ springeropen.com 